5 Research Square

\title{
Evaluating the Presence of Paresthesia in Patients with Juxta-apical Radiolucency after Third Molar Surgery: A Case-control Study
}

\section{Mahvash Hasani}

Shiraz University of Medical Sciences

\section{Nasim Razavi}

Shiraz University of Medical Sciences

Abdolaziz Haghnegahdar ( $\square$ hasani_m@sums.ac.ir)

Shiraz University of Medical Sciences

Motahhareh Zarifi

Shiraz University of Medical Sciences

\section{Research Article}

Keywords: Juxta-apical radiolucency, Paresthesia, Inferior alveolar nerve, Cone-beam computed tomography

Posted Date: February 23rd, 2021

DOl: https://doi.org/10.21203/rs.3.rs-220280/v1

License: (9) This work is licensed under a Creative Commons Attribution 4.0 International License. Read Full License 


\section{Abstract}

Background: Juxta-apical radiolucency (JAR) has been presented as a radiographic sign, suggestive of the IAN injury through third molar surgery. This study aimed to evaluate the relation of JAR with paresthesia in cone-beam computed tomography (CBCT) images and to determine whether the presence of JAR is related to tooth angulation, proximity to the mandibular canal, position to the IAN and thinning of the cortical plates.

Methods: Of an initial sample of 545 mandibular third molars, a total of $75 \mathrm{JAR}$ and 75 control teeth were evaluated by CBCT. The association of JAR with the IAN, position to IAN, lingual cortical plate thinning, and tooth angulation was investigated in this study. Temporary and permanent paresthesia were also examined in the subjects. Descriptive statistics, Chi-square test, and Fisher's exact test were performed for statistical analysis.

Results: A significant relationship was found between JAR and temporary paresthesia $(P=0.034)$. However, there was no case of permanent paresthesia. JAR showed no significant relationship with the tooth angulation, cortical plate thinning, position to IAN and proximity to the mandibular canal. The lingual position of JAR relative to the mandibular canal was related to the presence of paresthesia in the JAR group. Also, most cases of paresthesia showed some degree of lingual cortical plate thinning $(P=0.012)$.

Conclusion: JAR is generally in contact with the mandibular canal, and some degree of cortical thinning can be found in most cases. In this study, JAR was significantly related to temporary paresthesia. The present findings may indicate the increased risk of nerve injury during the surgical removal of third molars.

\section{Background}

The mandibular third molars are the most commonly impacted teeth [1]. Extraction of impacted or erupted mandibular third molars is one of the most frequent dentoalveolar surgical procedures [2]. These teeth are in close proximity to important structures, including the inferior alveolar nerve, the lingual nerve, and the adjacent second molars. Generally, injury to the inferior alveolar nerve is a major concern for surgeons. The incidence of temporary and permanent inferior alveolar nerve neuropathy, associated with mandibular third molar surgeries, is estimated at $1-20 \%$ and $0-3.6 \%$, respectively $[3,4]$. The majority of injuries result in transient sensory disturbances, while in some cases, permanent paresthesia, hypoesthesia, or even dysesthesia may occur. These sensory disturbances can cause speech and mastication problems and adversely affect the patient's quality of life. They also constitute one of the most frequent causes of medical complaints and litigation [5].

The radiographic position of the mandibular third molars relative to the mandibular canal has been shown to be useful in assessing the risk of damage to the inferior alveolar nerve following extraction [68]. Seven radiographic signs can increase the incidence of injury to the inferior alveolar nerve, including 
the darkening of the roots, diversion of the canal, and interruption of the white line of the canal, which are assumed to be the best predictive signs of neurosensory deficits [9]. In 2005, Renton et al. introduced the juxta-apical area (JAA) or juxta-apical radiolucency (JAR) as a new predictive sign [4]. JAR is a welldefined area of radiolucency that is apical or lateral to the roots of mandibular third molars.

In 2010, Umar et al. showed that JAR is a large cancellous bone space, which is superimposed on the inferior alveolar canal and is not always in contact with it [10]. Other researchers have also investigated the relationship between JAR, the alveolar canal, and the third molar roots [11-13]. They established that JAR is commonly located buccally or superiorly to the canal and introduced the concept of a JARassociated parasthesia. They suggested that thinning of the cortical plate could be responsible for postoperative paresthesia following the extraction of third molars [12, 14]. Moreover, Gilvetti et al. evaluated paresthesia in patients with JAR following the third molar surgery, based on panoramic radiography. According to their study, the presence of JAR is not a reliable predictor of the risk of permanent injury to the inferior alveolar nerve [9].

There are some controversies regarding the nature of the JAR as a risk factor for inferior alveolar injuries. Considering the limitations of previous studies, which mostly applied panoramic radiography $[9,13]$ and lacked a control group $[9,15]$, in this case-control study, we aimed to determine the relationship between the presence of JAR in cone-beam computed tomography (CBCT) images and the presence of paresthesia after mandibular third molar surgeries. Moreover, we scrutinized whether the presence of JAR is related to tooth angulation, proximity to the mandibular canal, position to the IAN and thinning of the cortical plates.

\section{Methods}

This case-control study was approved by the ethics committee of Shiraz University of Medical Sciences, Shiraz, Iran (\#IR.SUMS.DENTAI.REC.1399.041). This study was in compliance with the Helsinki Declaration. Informed contest was taken from all patients or their guardians. The study population consisted of all patients who underwent lower third molar removal from January 2019 to February 2020, with CBCT images available in the dental school database of Shiraz University of Medical Sciences. Patients who had at least one lower third molar, aged $\geq 18$ years at the time of surgery, were included in this study. On the other hand, patients were excluded if their lower third molars were associated with active caries lesions extending into the dentine; large restorations; endodontic treatments; periapical lesions; cysts; tumors; or history of trauma. Also, patients with lower third molars, showing other radiographic signs of IAN injury including the darkening of the roots, diversion of the canal, and interruption of the white line of the canal, and those whose roots were not fully formed, were excluded.

The CBCT images were acquired using a CBCT system (NewTom VGi, QR s.r.l., Italy) with a flat panel detector (FPD). The patients were positioned in the Frankfort plane parallel to the floor. The acquisition parameters were set as follows: current of $110 \mathrm{kVp}$; exposure time of 1.8 seconds; and field of view of 10 $\mathrm{cm} \times 5 \mathrm{~cm}$. The field of view encompassed the mandibular third molars and the surrounding structures. $A$ 
voxel size of $0.3 \mathrm{~mm}$, with an interslice gap of $0.3 \mathrm{~mm}$, was used to acquire images. The CBCT images were reviewed in NNT viewer version 8.0 under dimmed light. Also, image adjustments (e.g., zoom, brightness, and contrast) were allowed.

Two observers reviewed the CBCT images, and cases with and without JAR were selected. In case of disagreement between the observers, they discussed their findings until a consensus was reached. A total of 75 teeth with JAR (case group) and 75 teeth without JAR (control group) were selected randomly. The mandibular third molars were evaluated in three aspects (sagittal, coronal, and axial) in CBCT images. The observers searched for JAR as a well-defined area of radiolucency, apical or lateral to the roots of mandibular third molars (Fig. 1).

The CBCT images were classified regarding the type of impaction as vertical, horizontal, mesioangular, and distoangular, based on Winter's classification [16] (Fig. 2).

The position of JAR relative to the mandibular canal was categorized as buccal, lingual, superior, and inferior (Fig. 3).

In the control group, the location of the tooth apex relative to the mandibular canal was recorded. The proximity of JAR to the IAN canal was determined in three categories: 1) distant; 2) in contact with IAN with preservation of the cortical plate; and 3) in contact with IAN without preservation of the cortical plate (Fig. 4).

The thinning of lingual cortical plates in the JAR region was recorded, according to the methodology proposed by Kapila et al. [17]. Briefly, the narrowest point of the cortical plate close to JAR was recorded and classified as $\mathrm{J} 1, \mathrm{~J} 2$, and $\mathrm{J} 3$ when the remaining cortical thickness was three-fourths, one-half, and one-fourth of the maximum cortical thickness, respectively. The presence of cortical perforation was also recorded as $\mathrm{J} 4$, while an intact cortical plate was reported as $\mathrm{J0}$ (Fig. 5). In the control group, the apex of teeth was considered rather than JAR.

The case and control groups were asked for changes in sensation at three-time points, that is, the initial days after surgery (temporary paresthesia) and three and six months after surgery (permanent paresthesia). The patients were directly asked about any tingling sensation or numbness of the lips or chin to determine impairments in each examination period based on Loescher et al. study[5].

\section{Statistical analysis}

Data were recorded in IBM SPSS for Windows version 26 (IBM Corp., Armonk, N.Y., USA). Chi-square and Fisher's exact tests were performed for evaluating the association of JAR with paresthesia, JAR position, proximity to IAN, cortical plate thinning, and sex in the case and control groups. Independent samples $t$ test was also used for comparing the age of the case and control groups. The level of significance was set at $P<0.05$. 


\section{Results}

A total of 332 patients (545 mandibular third molars), aged $\geq 18$ years, with complete root formation, were included in this study. Overall, 75 (13.76\%) mandibular third molars of 61 (18.37\%) patients showed JAR. Only 14 out of 61 (22.95\%) patients had bilateral JAR. On the other hand, 75 mandibular third molars of 56 patients without JAR were selected as the control group.

\section{Relationship between JAR and gender}

In the JAR group, $16(26.2 \%)$ patients were male, and 45 (73.8\%) were female, whereas in the control group, 25 (44.6\%) patients were male, and 31 (55.4\%) were female. Considering the gender predilection, a significant difference was observed in the prevalence of JAR between the two groups. In other words, the female patients showed significantly more JAR than males $(P=0.037)$ (Table 1$)$. 
Table 1

JAR and its relation to anatomical structures and dental variables versus the control group

\begin{tabular}{|c|c|c|c|c|}
\hline Variables & & JAR group & Control group & $\begin{array}{l}\mathrm{P} \text { - } \\
\text { value }\end{array}$ \\
\hline \multirow{2}{*}{$\begin{array}{l}\text { Sex } \\
\text { No. (\%) }\end{array}$} & Female & 45 (73.8\%) & 31 (55.4\%) & \multirow[t]{2}{*}{0.037} \\
\hline & Male & $16(26.2 \%)$ & 25 (44.6\%) & \\
\hline \multirow{2}{*}{\multicolumn{2}{|c|}{$\begin{array}{l}\text { Age } \\
\text { Mean (SD) }\end{array}$}} & $\begin{array}{l}26.43( \pm \\
4.372)\end{array}$ & $\begin{array}{l}26.96( \pm \\
5.023)\end{array}$ & \multirow[t]{2}{*}{0.537} \\
\hline & & & & \\
\hline \multirow{4}{*}{$\begin{array}{l}\text { Tooth angulation } \\
\text { No. (\%) }\end{array}$} & Mesioangular & $41(54.7 \%)$ & $41(54.7 \%)$ & \multirow[t]{4}{*}{0.346} \\
\hline & Distoangular & $8(10.7 \%)$ & $7(9.3 \%)$ & \\
\hline & Vertical & 17 (22.7\%) & $11(14.7 \%)$ & \\
\hline & Horizontal & $9(12.0 \%)$ & $16(21.3 \%)$ & \\
\hline \multirow{3}{*}{$\begin{array}{l}\text { Proximity to IAN } \\
\text { No. (\%) }\end{array}$} & Distant & $7(9.3 \%)$ & $7(9.3 \%)$ & \multirow[t]{3}{*}{0.578} \\
\hline & Preserved cortex & $17(22.7 \%)$ & $12(16.0 \%)$ & \\
\hline & $\begin{array}{l}\text { Without preserved } \\
\text { cortex }\end{array}$ & $51(68.0 \%)$ & $56(74.7 \%)$ & \\
\hline \multirow{4}{*}{$\begin{array}{l}\text { Position } \\
\text { No. (\%) }\end{array}$} & Superior & $17(22.7 \%)$ & $30(40.0 \%)$ & \multirow[t]{4}{*}{0.122} \\
\hline & Inferior & $8(10.7 \%)$ & $8(10.7 \%)$ & \\
\hline & Buccal & $23(30.7 \%)$ & $15(20.0 \%)$ & \\
\hline & Lingual & $27(36.0 \%)$ & $22(29.3 \%)$ & \\
\hline \multirow{5}{*}{$\begin{array}{l}\text { Lingual cortical plate } \\
\text { thinning } \\
\text { No. (\%) }\end{array}$} & J0 & $12(16.0 \%)$ & $17(22.7 \%)$ & \multirow[t]{5}{*}{0.626} \\
\hline & J1 & $12(16.0 \%)$ & $9(12.0 \%)$ & \\
\hline & $\mathrm{J} 2$ & $22(29.3 \%)$ & $20(26.7 \%)$ & \\
\hline & J3 & $17(22.7 \%)$ & $21(28.0 \%)$ & \\
\hline & J4 & $12(16.0 \%)$ & $8(10.7 \%)$ & \\
\hline \multirow{2}{*}{$\begin{array}{l}\text { Temporary paresthesia } \\
\text { No. (\%) }\end{array}$} & Positive & $23(30.7 \%)$ & $12(16.0 \%)$ & \multirow[t]{2}{*}{0.034} \\
\hline & Negative & $52(69.3 \%)$ & $63(84.0 \%)$ & \\
\hline \multirow{2}{*}{\multicolumn{2}{|c|}{$\begin{array}{l}\text { Permanent paresthesia } \\
\text { №. }(\%)\end{array}$}} & $0(0.0 \%)$ & $0(0.0 \%)$ & \\
\hline & & & & \\
\hline
\end{tabular}

Relationship between JAR and age 
The mean (SD) age of the JAR group was $26.43( \pm 4.372)$ years, and the mean (SD) age of the control group was 26.96 ( \pm 5.023$)$ years. There was no significant difference between the two groups in terms of age $(P=0.537)$ (Table 1$)$.

\section{Relationship between JAR and temporary paresthesia after surgery}

Twenty-three cases of JAR (30.7\%) showed temporary paresthesia, whereas in the control group, only 12 cases showed temporary paresthesia after surgery. The prevalence of temporary paresthesia after surgery in the JAR group was significantly higher than the control group $(P=0.034)$. However, the prevalence of paresthesia was similar in males and females. Overall, 14 out of 45 female patients (31.11\%) and five out of 16 male patients (31.25\%) with JAR showed temporary paresthesia. Also, 12 out of 32 patients (37.5\%) under 25 years of age, 4 out of 17 patients $(23.52 \%)$ aged $26-30$ years, and three out of 12 patients (25.0\%) over 30 years showed temporary paresthesia in the JAR group.

\section{Relationship between JAR and permanent paresthesia after surgery}

Three and six months after surgery, all patients with paresthesia in the JAR and control groups recovered, and no permanent paresthesia was reported.

\section{Relationship between JAR and tooth angulation}

In the JAR group, 41 (54.7\%) teeth were mesioangular, 17 (22.7\%) were vertical, 9 (12.0\%) were horizontal, and 8 (10.7\%) were distoangular. In the control group, 41 (54.7\%) teeth were mesioangular, 16 (21.3\%) were horizontal, 11 (14.7\%) were vertical, and 7 (9.3\%) were distoangular. The mesioangular teeth were the most common in both groups. Regarding the tooth angulation, no significant difference was detected between the case and control groups $(P=0.346)$ (Table 1$)$.

\section{Relationship between tooth angulation and temporary paresthesia}

Of 23 teeth with the signs of JAR and temporary paresthesia after surgery, 9 (39.1\%) were mesioangular, $8(34.8 \%)$ were vertical, 4 (17.4\%) were horizontal, and 2 (8.7\%) were distoangular. The tooth angulation in the control group with temporary paresthesia is shown in Table 2. Although the number of vertically angulated teeth with paresthesia in the JAR group was higher than the control group, there was no significant relationship between the tooth angulation and temporary paresthesia after surgery $(P=0.362)$. 
Table 2

The JAR relation to anatomical structures and dental variables considering temporary paresthesia

\begin{tabular}{|c|c|c|c|c|}
\hline Variables & & JAR group & Control group & $\begin{array}{l}\mathrm{P} \text { - } \\
\text { value }\end{array}$ \\
\hline \multirow{2}{*}{$\begin{array}{l}\text { Sex } \\
\text { No. (\%) }\end{array}$} & Female & 14 (73.7\%) & $6(60.0 \%)$ & \multirow[t]{2}{*}{0.675} \\
\hline & Male & $5(26.3 \%)$ & $4(40.0 \%)$ & \\
\hline \multicolumn{2}{|l|}{$\begin{array}{l}\text { Age } \\
\text { Mean (SD) }\end{array}$} & $\begin{array}{l}26.05( \pm \\
3.734)\end{array}$ & $\begin{array}{l}26.30( \pm \\
4.001)\end{array}$ & 0.870 \\
\hline \multirow{4}{*}{$\begin{array}{l}\text { Tooth angulation } \\
\text { No. (\%) }\end{array}$} & Mesioangular & 9 (39.1\%) & $7(58.3 \%)$ & \multirow[t]{4}{*}{0.362} \\
\hline & Distoangular & $2(8.7 \%)$ & $1(8.3 \%)$ & \\
\hline & Vertical & $8(34.8 \%)$ & $1(8.3 \%)$ & \\
\hline & Horizontal & $4(17.4 \%)$ & $3(25.0 \%)$ & \\
\hline \multirow{3}{*}{$\begin{array}{l}\text { Proximity to IAN } \\
\text { No. (\%) }\end{array}$} & Distant & $3(13.0 \%)$ & $0(0.0 \%)$ & \multirow[t]{3}{*}{0.305} \\
\hline & Preserved cortex & $6(26.1 \%)$ & $4(33.3 \%)$ & \\
\hline & $\begin{array}{l}\text { Without preserved } \\
\text { cortex }\end{array}$ & $14(60.9 \%)$ & $8(66.7 \%)$ & \\
\hline \multirow{4}{*}{$\begin{array}{l}\text { Position } \\
\text { No. (\%) }\end{array}$} & Superior & $5(21.7 \%)$ & $6(50.0 \%)$ & \multirow[t]{4}{*}{0.238} \\
\hline & Inferior & $3(13.0 \%)$ & $2(16.7 \%)$ & \\
\hline & Buccal & $4(17.4 \%)$ & $2(16.7 \%)$ & \\
\hline & Lingual & $11(47.8 \%)$ & $2(16.7 \%)$ & \\
\hline \multirow{5}{*}{$\begin{array}{l}\text { Lingual cortical plate } \\
\text { thinning } \\
\text { No. (\%) }\end{array}$} & $\mathrm{JO}$ & $1(4.3 \%)$ & $5(41.7 \%)$ & \multirow[t]{5}{*}{0.012} \\
\hline & J1 & $6(26.1 \%)$ & $1(8.3 \%)$ & \\
\hline & $\mathrm{J} 2$ & $5(21.7 \%)$ & $1(8.3 \%)$ & \\
\hline & J3 & $6(26.1 \%)$ & $3(25.0 \%)$ & \\
\hline & J4 & $5(21.7 \%)$ & $2(16.7 \%)$ & \\
\hline
\end{tabular}

\section{Relationship between JAR and proximity to IAN}

Fifty-one JARs (68.0\%) were associated with IAN without preservation of the cortical boarder, $17(22.7 \%)$ were in direct contact with IAN with preservation of the cortical boarder, and only 7 (9.3\%) were completely distant from IAN. In the control group, 56 tooth apices $(74.7 \%)$ were associated with IAN without preservation of the cortical boarder, $12(16.0 \%)$ were in direct contact with IAN with preservation of the cortical boarder, and 7 (9.3\%) were completely distant from it. There was no significant difference between the two groups regarding the tooth proximity to IAN $(P=0.578)$ (Table 1). 


\section{Relationship between tooth proximity to IAN and temporary paresthesia}

In the JAR group, 20 out of 23 teeth in contact with IAN showed temporary paresthesia, whereas in the control group, 12 out of 12 teeth in contact with IAN, with or without cortical preservation, showed paresthesia. The proximity of teeth with temporary paresthesia to IAN is presented in Table 2. There was no significant relationship between proximity to IAN and temporary paresthesia in the case and control groups $(P=0.305)$.

\section{JAR position relative to the mandibular canal}

Seventeen cases of JAR (22.7\%) were superior to the mandibular canal, 8 (10.7\%) were inferior, 23 (30.7\%) were buccal, and 27 (36.0\%) were lingual. In the control group, the apex was superior to the mandibular canal in $30(40.0 \%)$ teeth, inferior in 8 (10.7\%) teeth, buccal in $15(30.7 \%)$ teeth, and lingual in $22(29.3 \%)$ teeth. In the JAR group, the most common position of JAR was lingual to the mandibular canal, while in the control group, it was superior to the mandibular canal; however, there was no significant difference between the two groups $(P=0.122)$ (Table 1).

\section{Relationship between tooth position relative to IAN and temporary paresthesia}

Most JAR teeth (11/23) showed paresthesia when they were lingual to IAN, whereas most control teeth $(6 / 12)$ with paresthesia were superior to the mandibular canal. There was a significant relationship between the JAR position and the presence of paresthesia $(P=0.052)$. The position of teeth showing paresthesia is presented in Table 2 .

\section{Relationship between JAR and lingual cortical plate}

In the JAR group, $12(16.0 \%)$ teeth had an intact lingual cortical plate (J0), while $12(16.0 \%)$ teeth were classified as J1, 22 (29.3\%) as J2, and 17 (22.7\%) as J3. Also, 12 (16\%) teeth showed completely perforated lingual plates (J4). The lingual cortical thinning in the control group is shown in Table 2. Most JAR (84.0\%) and control (77.3\%) teeth showed some degree of cortical thinning, and there was no significant difference between the JAR and control groups $(P=0.626)$ (Table 1).

\section{Relationship between lingual cortical plate thinning and temporary paresthesia}

In the JAR group, most (95.7\%) teeth with temporary paresthesia showed lingual cortical plate thinning, whereas, in the control group, only seven out of 12 teeth (58.3\%) with temporary paresthesia showed lingual cortical plate thinning. Temporary paresthesia and lingual cortical plate thinning showed a significant relationship $(P=0.012)$. Table 2 presents the lingual cortical plate thinning in patients with temporary paresthesia. 


\section{Discussion}

In this study, we evaluated the presence of JAR and its relationship with the presence of paresthesia in $\mathrm{CBCT}$ images. Also, thinning of the lingual cortical plate, JAR position relative to IAN, and proximity of JAR to the mandibular canal were evaluated in the case and control groups. There was a significant association between JAR and the presence of temporary paresthesia $(P=0.034)$, whereas no cases of permanent paresthesia were detected three months after surgery in either of the groups.

Seven radiological signs are considered to be indicative of a close relationship between the impacted mandibular third molars and the inferior alveolar canal. Only three of these signs seem to be significantly related to the inferior alveolar nerve injury, including the canal diversion, darkening of the root, and interruption in the white line of IAN [8]. Moreover, JAR and deviation of the canal were significantly associated with nerve injury [4]. In the present study, the main risk factor for injury was the presence of JAR in CBCT images.

Recently, it has been hypothesized that JAR is the initial area of focal osseous dysplasia [14]. In this regard, Umar et al. [10] reported that JAR originates from the superimposition of a large cancellous bone on the mandibular canal. Also, Gilvetti et al. [9] studied 50 cases of JAR in panoramic images and found no temporary or permanent paresthesia after at least 18 months. Yalcin and Artas [15] confirmed this result, as they found no significant relationship between JAR and the mandibular canal. In a study by Nascimento et al., in most JAR cases, the mandibular canal is positioned lingual to the third molar and contacts the JAR [12]. In our study population, $18.37 \%$ of the patients had JAR signs in CBCT images. In two studies by Nascimento et al. [12,14], $15.9 \%$ and $32.6 \%$ of patients showed JAR in CBCT images. Also, in the study by Yalcin and Artas, $33 \%$ of patients showed JAR in CBCT images. In our study, the number of female patients was significantly higher in the JAR group than the control group $(P=0.037)$. As reported by Nascimento et al., the probability of JAR identification in female patients is almost twice as high as male patients [13].

In the present study, the majority of JARs (90.7\%) were in contact with IAN, with or without cortical boarder preservation. This finding is in line with the results reported by Nascimento et al., which revealed that only $6.4 \%$ of cases were located distant from the mandibular canal, while most cases were in contact with the canal [12]. In contrast, a study by Kapila et al. showed that $28.57 \%$ of JAR cases were in contact with the mandibular canal in CBCT images [18]. Similarly, Yalcin and Artas found that JAR was mostly distant from the mandibular canal (76.3\%) [15].

Overall, determining the position of the JAR is important, considering the possible need for special attention during surgery [12]. In this regard, Ghaeminia reported that the lingual side of the mandibular canal in the third molar region is more susceptible to unfavorable forces during surgery [19]. Regarding the JAR position, different outcomes have been reported in the literature. Nascimento et al. found that JAR was in the lingual position relative to IAN (59.6\%) [12], while in a study by Kapila et al., the most frequent positions were buccal and superior to IAN [17]. Also, Yalcin and Artas showed that JAR was 
mostly in the superior position [15]. In our study, lingual and buccal positions were the most common ones, and most JARs with paresthesia were on the lingual side of the mandibular canal.

Moreover, Yalcin and Artas found cortical thinning in $67 \%$ of cases in their study. Also, Kapila et al. reported that thinning of cortical plates was significantly more common in JAR cases than the controls (70\% vs. $37 \%$ ). They postulated that cortical plate thinning could be responsible for postoperative paresthesia following the extraction of third molars. In the present study, $84 \%$ of JAR cases showed at least some degree of lingual cortical plate thinning, and even $16 \%$ of cases were perforated. However, we found no significant relationship between the presence of JAR and thinning of the cortical plate $(P=$ 0.626), although most cases of JAR with paresthesia (95.7\%) showed some degree of cortical thinning.

In the current study, most cases of JAR (54.7\%) were detected in teeth with a mesioangular position; however, there was no significant difference between the groups $(P=0.346)$. In this regard, Kapila et al. found the mesioangular position to be the most common one [18]; however, they did not include a control group to analyze the significance of their findings. On the other hand, in the study by Nascimento et al., JAR was related to vertically positioned teeth [13], although panoramic images were examined in their study. Yalcin and Artas also found that the vertical position was the most common angulation related to JAR in CBCT images; however, they did not include a control group in their study [15].

Loescher et al. postulated that the patient's subjective report is the most sensitive indicator of abnormal sensation and that tests cannot detect minor sensory disturbances [5]. Therefore, we did not use any quantitative tests in our study and identified the patients qualitatively by asking them about any tingling sensation or numbness of the lips or the chin. In their study, the patient follow-up was conducted via phone calls, as such follow-ups can increase the number of participants in the research and is more costeffective [20].

Overall, the current study revealed that temporary paresthesia is more common in patients with JAR (on CBCT images) than the control group. However, no permanent paresthesia was detected in the threemonth follow-up. Consistent with our findings, a study by Alling et al. showed that $96 \%$ of inferior alveolar nerve injuries recovered within 4-8 weeks after surgery [21]. There is only another study investigating the relationship between paresthesia and JAR in panoramic images, which indicated no significant relationship [9]. However, our study was based on CBCT images, as JAR detection is more accurate in CBCT images than panoramic images [14].

\section{Conclusion}

JAR was significantly associated with temporary paresthesia, but not permanent paresthesia. Also, JAR was significantly more common in female patients than males. The lingual position of JAR relative to the mandibular canal was associated with the presence of paresthesia in the JAR group. Most cases of paresthesia showed some degree of lingual cortical plate thinning. Further research with a larger sample size is needed to confirm the association of JAR with paresthesia. 


\section{Declarations}

\section{Ethical approval and consent to participate}

This study is approved by the local Ethical Committee of Shiraz University of Medical

Sciences(\#IR.SUMS.DENTAI.REC.1399.041).

\section{Consent for publication}

Not applicable.

\section{Availability of data and materials}

The datasets used and analyzed during the current study are available from the corresponding author.

\section{Competing interests}

The authors declare that they have no competing interests.

\section{Funding}

This study was supported by the vice-chancellery of Shiraz University of Medical Sciences (Grant\#20879).

\section{Authors' Contributions}

Study concepts: HM, HA, RN. Study design: HM, HA, RN. Data acquisition: ZM, HM. Quality control of data and algorithms: HM. Data analysis and interpretation: HM, ZM. Manuscript preparation: ZM, HM, HA, RN. Manuscript editing: HM, HA. All authors read and approved the final manuscript.

\section{Acknowledgements}

The authors would like to acknowledge the vice-chancellery of Shiraz University of Medical Sciences, for supporting the research (Grant\#20879). The authors thank the Research Consultation Center for the statistical analysis. This manuscript is based on the thesis of Dr. Motahhareh Zarifı.

\section{Author details}


1, 2,3 Department of Oral and Maxillofacial Radiology, School of Dentistry, Shiraz University of Medical Science, Shiraz, Iran. ${ }^{4}$ School of Dentistry, Shiraz University of Medical Science, Shiraz, Iran.

\section{References}

1. Mehdizadeh M, Haghanifar S, Seyedmajidi M, Bijani A, Soufizadeh R: Radiographic evaluation of impacted third molars and their complications in a group of Iranian population. journal of research and practice in dentistry 2014, 2014:m1-11.

2. Grossi GB, Maiorana C, Garramone RA, Borgonovo A, Creminelli L, Santoro F: Assessing postoperative discomfort after third molar surgery: a prospective study. Journal of oral and maxillofacial surgery 2007, 65(5):901-917.

3. Renton T: Oral surgery: part 4. Minimising and managing nerve injuries and other complications. British dental journal 2013, 215(8):393.

4. Renton T, Hankins M, Sproate C, McGurk M: A randomised controlled clinical trial to compare the incidence of injury to the inferior alveolar nerve as a result of coronectomy and removal of mandibular third molars. British Journal of Oral and Maxillofacial Surgery 2005, 43(1):7-12.

5. Loescher A, Smith K, Robinson P: Nerve damage and third molar removal. Dental update 2003, 30(7):375-382.

6. Kipp DP, Goldstein BH, Weiss WW: Dysesthesia after mandibular third molar surgery: a retrospective study and analysis of 1,377 surgical procedures. The Journal of the American Dental Association 1980, 100(2):185-192.

7. Wofford DT, Miller RI: Prospective study of dysesthesia following odontectomy of impacted mandibular third molars. Journal of oral and maxillofacial surgery 1987, 45(1):15-19.

8. Rood J, Shehab BN: The radiological prediction of inferior alveolar nerve injury during third molar surgery. British Journal of Oral and Maxillofacial Surgery 1990, 28(1):20-25.

9. Gilvetti C, Haria S, Gulati A: Is juxta-apical radiolucency a reliable risk factor for injury to the inferior alveolar nerve during removal of lower third molars? British Journal of Oral and Maxillofacial Surgery 2019, 57(5):430-434.

10. Umar G, Bryant C, Obisesan $\mathrm{O}$, Rood J: Correlation of the radiological predictive factors of inferior alveolar nerve injury with cone beam computed tomography findings. Oral Surgery 2010, 3(3):72-82.

11. Khojastepour L, Ghasemi M, Rasti S, Hasani M: Evaluation of juxta-apical radiolucency as a risk factor for inferior alveolar nerve damage: A cone-beam computed tomography (cbct) study. Shiraz EMedical Journal 2020, 21(10):e93330.

12. Nascimento EHL, Oenning ACC, Nadaes MR, Ambrosano GMB, Haiter-Neto F, Freitas DQ: Juxta-apical radiolucency: relation to the mandibular canal and cortical plates based on cone beam CT imaging. Oral surgery, oral medicine, oral pathology and oral radiology 2017, 123(3):401-407.

13. Nascimento EHL, Oenning ACC, Nadaes MR, Ambrosano GMB, Haiter-Neto F, Freitas DQ: Juxta-Apical Radiolucency: Prevalence, Characterization, and Association With the Third Molar Status. Journal of 
Oral and Maxillofacial Surgery 2018, 76(4):716-724.

14. Nascimento EHL, Oenning ACC, Freire BB, Gaêta-Araujo H, Haiter-Neto F, Freitas DQ: Comparison of panoramic radiography and cone beam $\mathrm{CT}$ in the assessment of juxta-apical radiolucency. Dentomaxillofacial Radiology 2017, 47(1):20170198.

15. Yalcin E, Artas A: Juxta-apical radiolucency and relations with surrounding structures on cone-beam computed tomography. British Journal of Oral and Maxillofacial Surgery 2020.

16. Winter G: Principles of exodontia as applied to the impacted third molar: a complete treatise on the operative technic with clinical diagnoses and radiographic interpretations. St Louis: American Medical Book 1926:21-58.

17. Kapila R, Harada N, Araki K, Sano T, Goto T: Evaluation of juxta-apical radiolucency in cone beam CT images. Dentomaxillofacial Radiology 2014, 43(5):20130402.

18. Kapila R, Harada N, Araki K, Sano T, Goto TK: Relationships between third-molar juxta-apical radiolucencies and mandibular canals in panoramic and cone beam computed tomography images. Oral surgery, oral medicine, oral pathology and oral radiology 2014, 117(5):640-644.

19. Ghaeminia H, Meijer G, Soehardi A, Borstlap W, Mulder J, Bergé S: Position of the impacted third molar in relation to the mandibular canal. Diagnostic accuracy of cone beam computed tomography compared with panoramic radiography. International journal of oral and maxillofacial surgery 2009, 38(9):964-971.

20. Wells JP, Roked Z, Moore SC, Sivarajasingam V: Telephone review after minor oral surgery. British Journal of Oral and Maxillofacial Surgery 2016, 54(5):526-530.

21. Alling CC: Dysesthesia of the lingual and inferior alveolar nerves following third molar surgery. Journal of Oral and Maxillofacial Surgery 1986, 44(6):454-457.

\section{Figures}




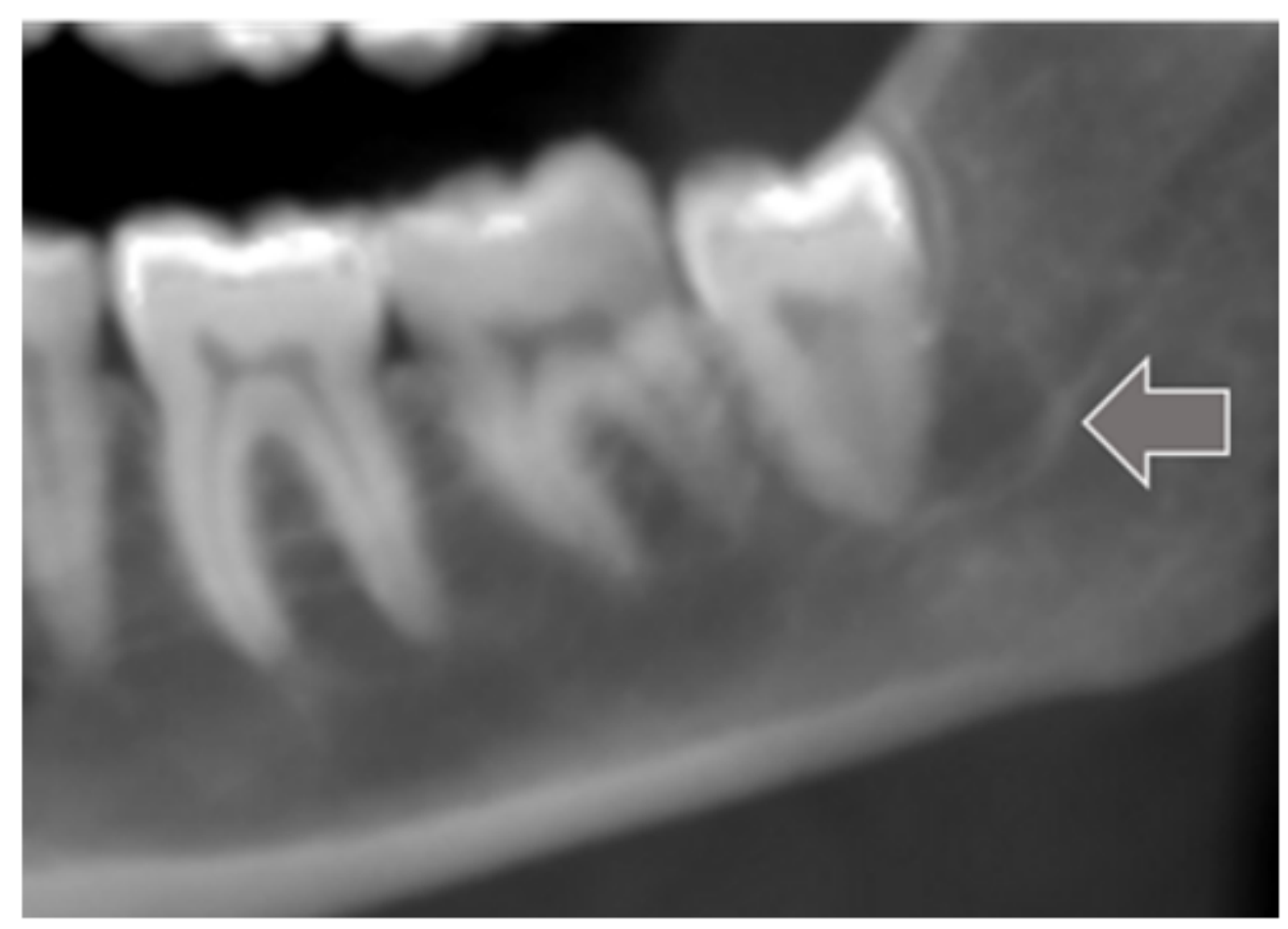

Figure 1

JAR associated with a lower third molar on reconstructed panoramic of CBCT images. 


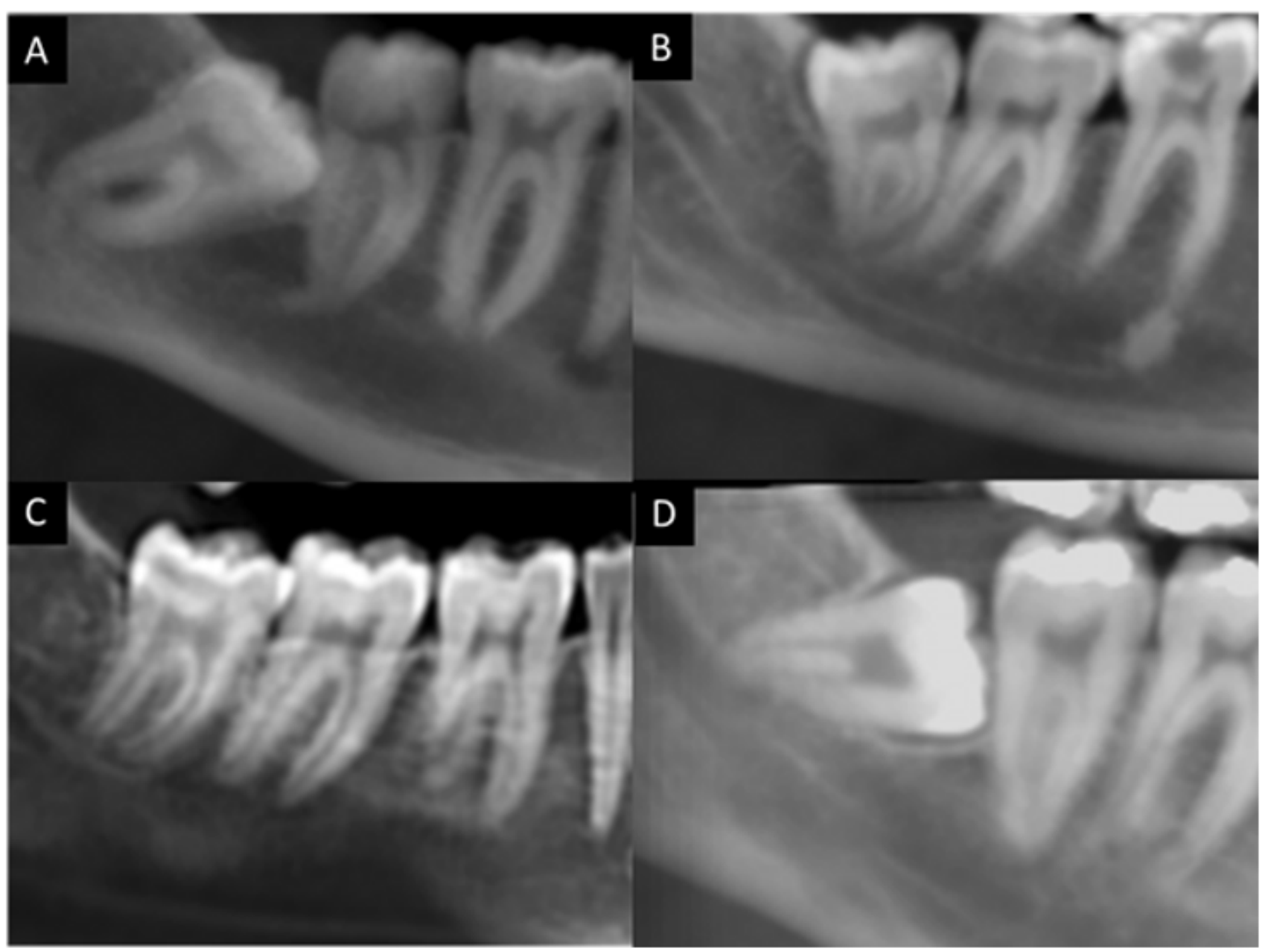

Figure 2

Classification of third molars based on angulation: mesioangular (A), distoangular (B), vertical (C) and horizontal (D). 


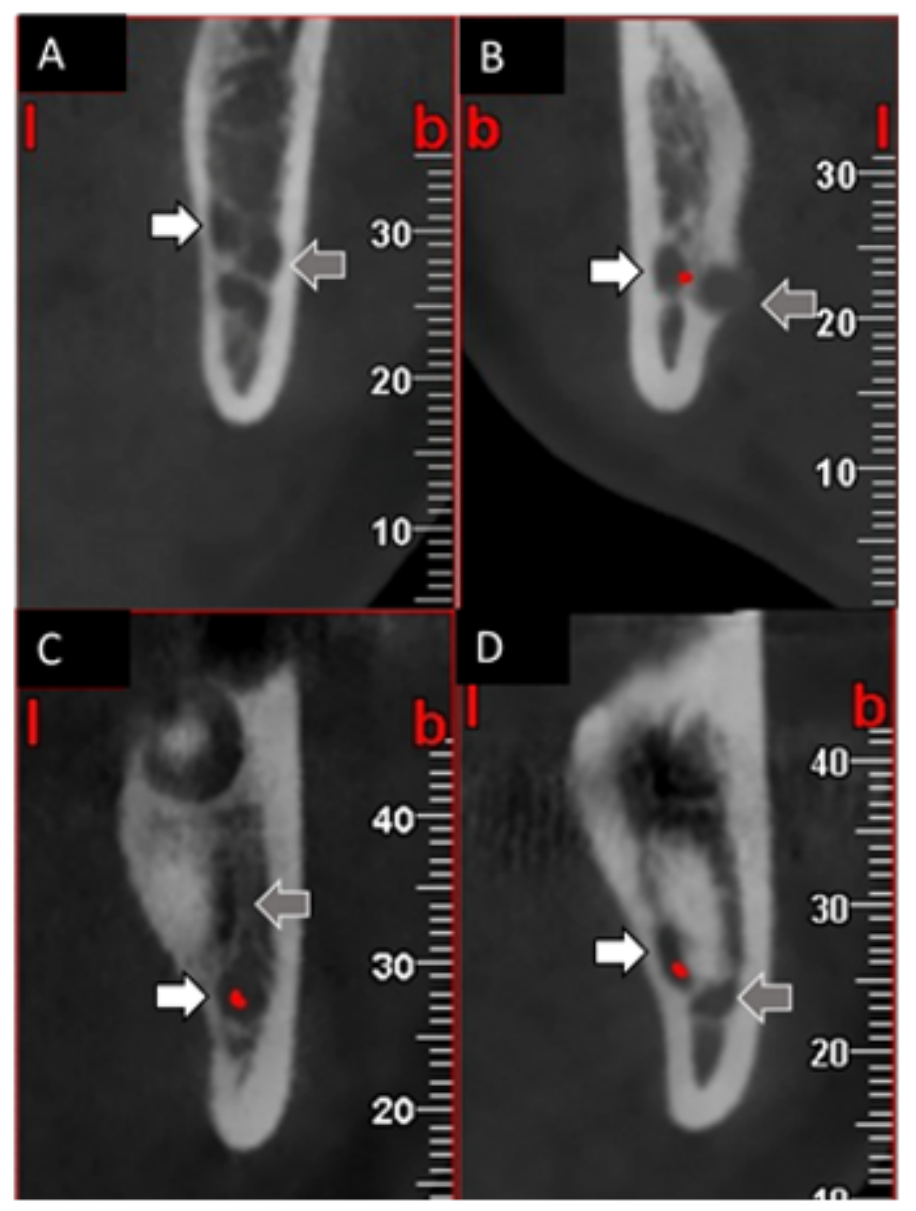

Figure 3

The position of JAR (gray arrows) relative to the mandibular canal (white arrows): buccal (A), lingual (B), superior (C), and inferior (D).

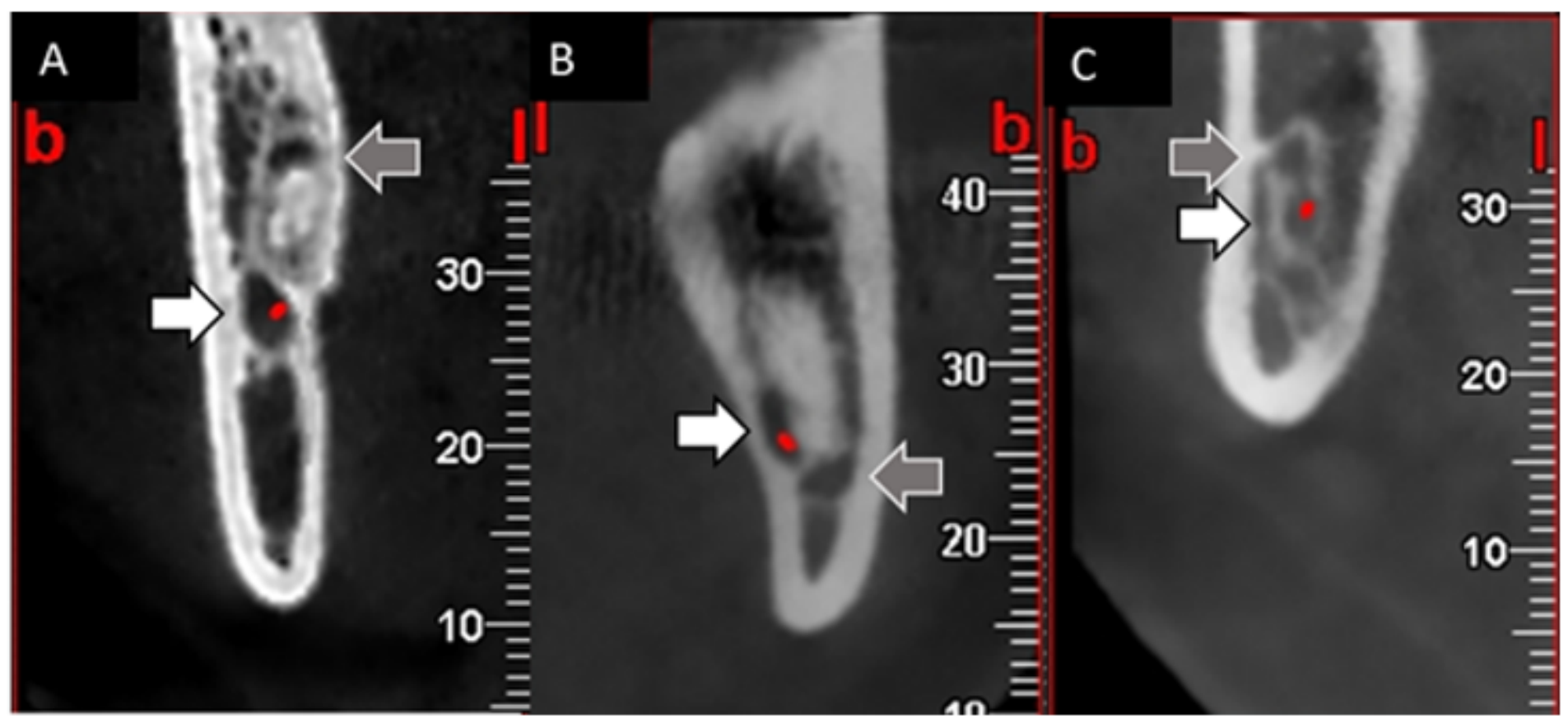




\section{Figure 4}

The relation of JAR (gray arrows) to IAN (white arrows): distant (A); in contact with IAN with preservation of the cortical plate (B); and in contact with IAN without preservation of the cortical plate (C).

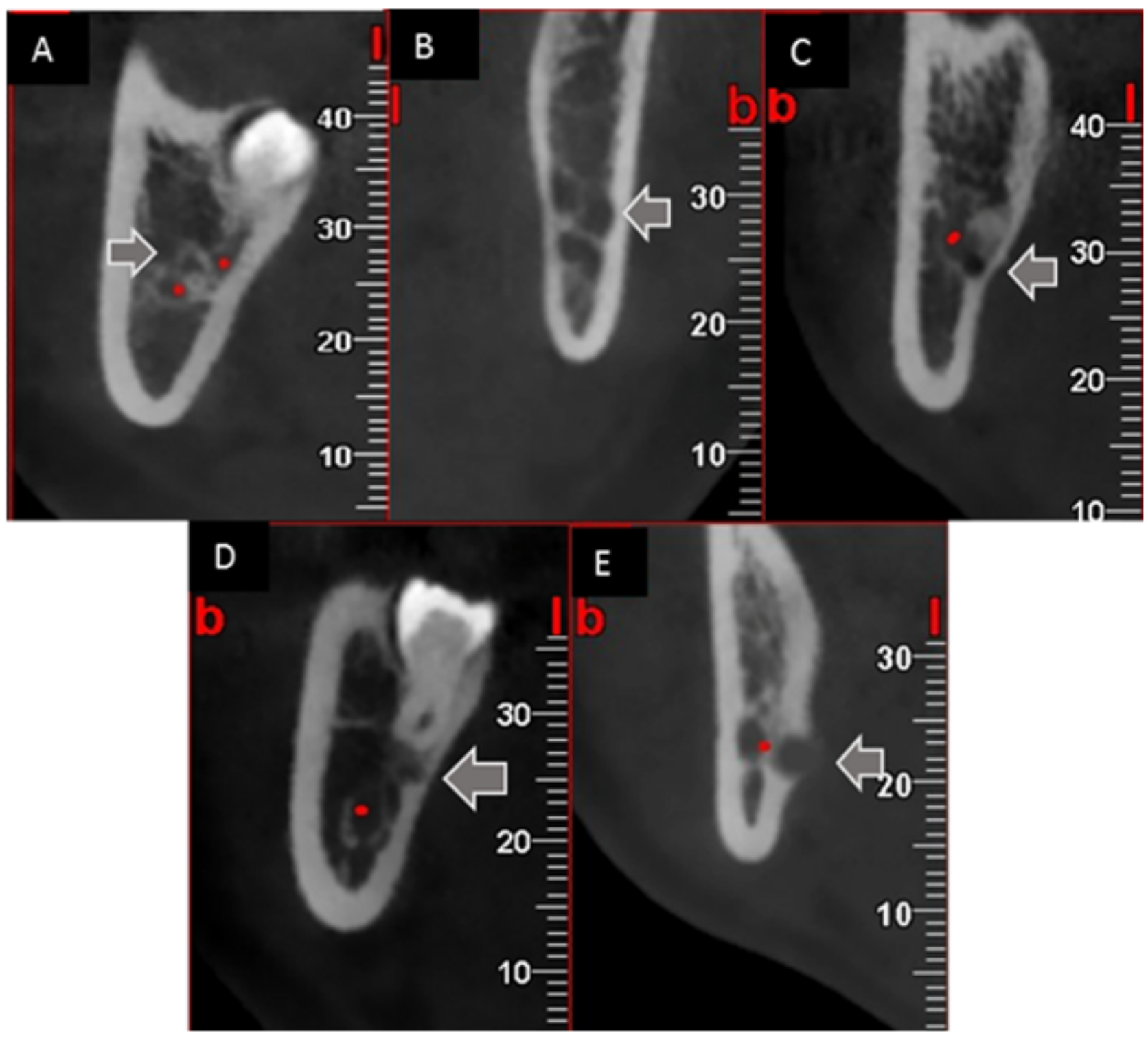

\section{Figure 5}

Lingual cortical plate thinning based on JAR (gray arrows) classification: J0 (A), J1 (B), J2(C), J3 (D), and J4 (E). 